\title{
Short Bowel Syndrome: Review of Treatment Options
}

\author{
Nina Oktafianti Marfu'ah, Herry Purbayu, Iswan Abbas Nusi, Poernomo Boedi Setiawan, Titong \\ Sugihartono, Ummi Maimunah, Ulfa Kholili, Budi Widodo, Muhammad Miftahussurur, Husin \\ Thamrin and Amie Vidyani \\ Department of Internal Disease, Faculty of Medicine, Universitas Airlangga, Dr. Soetomo General Hospital, \\ Surabaya, Indonesia \\ apji@fk.unair.ac.id
}

Keywords: Short Bowel Syndrome, Total Parenteral Nutrition, Bowel Resection, Malabsorption.

\begin{abstract}
Short bowel syndrome (SBS) is malabsorption due to intestinal surface area insufficiency. In Europe, the incidence of home Total Parenteral Nutrition (TPN) is approximately three cases per million people per year, and the prevalence is four cases per million per year, whereas most people who get home TPN are patients with SBS at 35\%. There are three types of SBS bowel resection types, namely ileocolonic, jejunocolonic, and jejunostomy. The main causes of SBS in adults are bowel resection associated with vascular disorders and Crohn's disease. Clinical manifestations of SBS are malabsorption of macronutrients, fluids, and electrolytes, vitamin and mineral deficiencies, diarrhea, gastric hypersecretion, wound healing and infection. SBS management includes nutrition management, pharmacological management, and surgical management. SBS complications include gallstones, oxalate kidney stones, liver diseases, d-lactate acidosis, peptic ulcers, and metabolic bone disease. This study is a literature review aiming to discuss treatment options for short bowel syndrome.
\end{abstract}

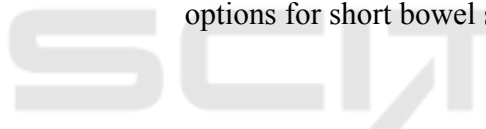

\section{INTRODUCTION}

Short bowel syndrome (SBS) is a malabsorption condition due to a decrease in the intestinal absorption area following a massive resection of the intestine. Survey data in Europe in 1997 showed an incidence of home total parenteral nutrition (TPN) of about three cases per million people per year, and the prevalence of four cases per million population per year, with the majority of those who have home TPN suffering from SBS (35\%) (Buchman, 2010; Fedorak, 2009).

It is difficult to determine the exact incidence of SBS. Data collection from the TPN home typically provides an incidence of the SBS heavy spectrum that requires TPN, making it less accurate because uncomplicated SBS patients who do not need a TPN home are not covered (Lamprecht, 2015). In America, in 1992 there were about 40,000 patients requiring TPN per year, of which $26 \%$ were SBS (Buchman, 2010). A retrospective review of pediatric referral centers estimating the incidence of SBS in neonates found 22 cases per 1,000 neonates entering the ICU and 25 cases per 100,000 live births (Fedorak, 2009).
Management of SBS patients is complex and individualized. The ultimate goal of the management of SBS patients is to maintain adequate nutritional and hydration status and to prevent occurrence of the underlying pathophysiological complications. Optimum management reduces morbidity and mortality. Thus, this literature review discusses the pathophysiology and management of SBS.

\section{DEFINITION}

SBS is defined as malabsorption due to insufficiency of the intestinal surface area so that it cannot absorb enough liquids, energy, or nutrients. SBS occurs when the length of the small intestine is left less than $200 \mathrm{~cm}$. Generally the length of the small intestine of adults ranges from 450-500 cm (Buchman, 2010). Measurements of intestinal length were performed from duodenojejunal flexure (Ligamentum Treitz), either directly measured at surgery, or evaluation of contrast images following the long axis of the rest of the intestine, or measurement at autopsy (Wall, 2013). Two fifths of proximal are jejunum, while three fifths are ileum. Colon length is generally 150 
cm (Fedorak, 2009). In wider terms, intestinal failure, caused by obstructive conditions, dysmotility, surgical resection, congenital defects, or loss of disease-related absorption, is characterized as an inability to maintain protein, energy, fluid, electrolyte, and micronutrient balance (Fedorak, 2009; Tappenden, 2014; Lamprecht, 2015).

There are three main types of bowel resection (Figure 1), namely Jejunoileal/ileocolonic, which is a limited ileal resection, usually accompanied by a cecostomy or right hemicolectomy. Jejunocolonic is a wide ileal resection with or without partial colectomy and Jejunostomy which is a widespread intestinal resection.
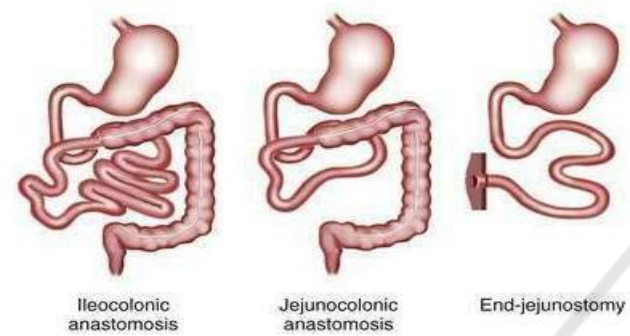

Figure 1: Three main types of bowel resection in SBS (Buchman, 2010).

\section{ETIOLOGY}

The incidence of prenatal vascular disorders that cause bowel atresia or volvulus is a major cause of SBS in children. The main causes of SBS in adults are bowel resection associated with vascular disorders and Crohn's disease, as shown in Table 1 (Fedorak, 2009).

\section{PATHOPHYSIOLOGY}

The consequence of massive bowel resection is the loss of absorption surface area causing malabsorption. The degree of malabsorption is determined by the length of residual intestine, the specific location of the resected intestine, and the residual intestinal adaptive adaptation process (Buchman, 2010; Fedorak, 2009).

1. The length of the remaining intestines

The length of residual intestine after resection determines the available surface area for absorption and determines the intestinal transit time. SBS may occur from massive single resection or recurrent short resection. About $50 \%(300 \mathrm{~cm})$ of the small intestine can usually be resected without causing
malabsorption/SBS. Resection of more than $75 \%$ $(450 \mathrm{~cm})$ often leads to malabsorption requiring enteral and parenteral replacement therapy (Fedorak, 2009).

Table 1: Causes of Short bowel syndrome.

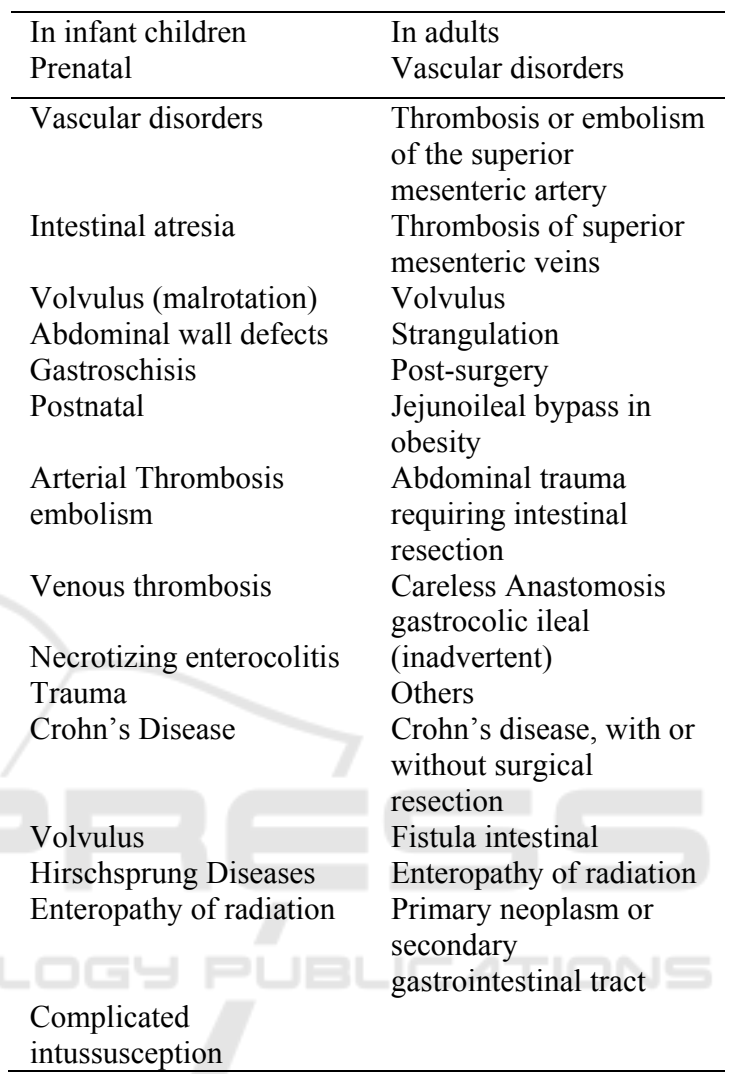

2. Specific intestinal location taken

a. Jejunum

Jejunum absorbs significant nutrients and liquids, but single jejunal resection usually causes little interference with absorption. This is due to two factors. The first factor: a tight junction jejunum is relatively leaky compared to the ileum or colon, resulting in significant back diffusion of the material transported into the intestinal lumen, causing fluid and electrolyte absorption in the jejunum to be less efficient (40\% efficiency) than in the ileum ( $75 \%$ efficiency). The second factor: the ileum is the gut section with the largest adaptation capacity, so it can compensate for almost all the absorption function of the jejunum. Therefore, jejunal resection is usually tolerated well (Fedorak, 2009). In contrast, the jejunum cannot compensate for the absorption of bile salts and vitamin B12 in the ileum. The location of 
nutrient absorption in the gastrointestinal tract can be seen in Figure 2.

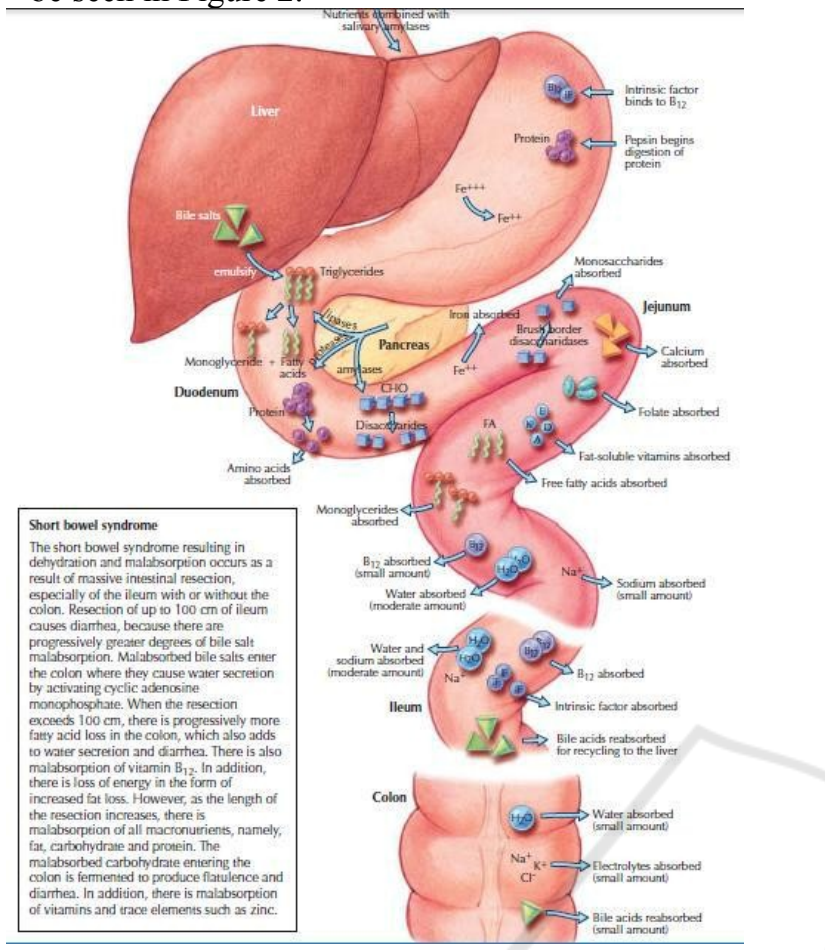

Figure 2: Absorption location of the normal gastrointestinal tract (Jeejeebhoy, 2002).

\section{b. Ileum}

The ileum is the main site of active absorption of bile acids and vitamin B12. Malabsorption of vitamin B12 occurs after resection of more than 60 $\mathrm{cm}$ of the ileum. Resection of more than $100 \mathrm{~cm}$ of the ileum usually decreases the active absorption of bile acids, so bile acids are retained in the lumen and overflow into the colon. This deconjugated bile acid directly stimulates the colon to secrete fluid and electrolytes, causing secretory diarrhea and SBS. During intestinal adaptation, the body compensates for the loss of bile acids by increasing bile acid stores through an eightfold increase in hepatic bile acid synthesis. More loss of ileum causes severe malabsorption of bile acids, where the loss exceeds the synthesis.

c. Colon

The main function of the colon is to absorb 1-2 liters of fluid received daily from the ileum (Fedorak, 2009). In total there are 8-9 liters of fluid reaching the small intestine, derived from oral intake and endogenous secretion; about $98 \%$ of these fluids are re-absorbed, including $80 \%$ by the small intestine and $18 \%$ by the colon (Tappenden, 2014).
Although the presence of the colon improves fluid and electrolyte absorption, it can also lead to maladaptive consequences. In addition, a combination of massive intestinal resection, fat malabsorption, and the presence of intact colon cause calcium oxalate kidney formation because free fatty acids in the colon are more likely to bind calcium, resulting in free oxalates absorbed by the colonic mucosa into the systemic circulation.

d. Availability of the ileocecal valve

The ileocecal valve separates the contents of the ileum and colon, providing a barrier that prevents migration of colonic microorganisms into the distal intestine. In addition it serves as a brake to prolong the intestinal transit time so as to increase absorption (Buchman, 2010; Fedorak, 2009). The removal of the ileocecal valve may cause bacterial overgrowth in the small intestine. This bacteria deconjugates the bile salts in the small intestine lumen, disrupting micelle formation, so the absorption of fat and fat-soluble vitamins decreases. Furthermore, this deconjugated bile salt spills into the colon and directly stimulates the secretion of fluid and colonic electrolytes and causes SBS. Intraluminal bacteria also use vitamin B12 for their metabolic processes, thus decreasing the availability of vitamin B12 for host absorption and exacerbating vitamin B12 deficiency. SBS patients who still have a colon and ileocecal valve have a good prognosis. If the ileocecal valve is taken, the tendency for SBS increases and is usually quite severe (Fedorak, 2009; Buchman, 2010; Seetharam and Rodrigues; 2011).

3. Intestinal Adaptation

The results of all these adaptive changes are increased surface area of intestinal absorption, increased microvillus enzyme activity and absorption capacity per unit of intestinal length. This adaptive process is more visible in residual ileum than residual jejunum. The adaptation process takes one to two years, and is highly dependent on intraluminal nutrients to maintain bowel structure and function. In inducing an adaptive process, SBS patients are encouraged to initiate oral intake as soon as possible in the postoperative phase (Fedorak, 2009; Buchman, 2010).

Intraluminal nutrients stimulate intestinal adaptation through three mechanisms: 1) Intraluminal nutrients stimulate morphological and functional adaptations of the intestine. Mucosal atrophy occurs when all the nutrients are administered parenterally because without exposure to intraluminal nutrients the adaptation does not 
occur, resulting in hypoplasia. In addition, nonnutritional ingredients do not stimulate mucosal growth; thus, the absorption or metabolism of luminal nutrients is important for intestinal adaptation processes; 2) Intraluminal nutrients stimulate the secretion of some trophic gastrointestinal hormones that function in intestinal growth and adaptation processes, such as: gastrin, cholecystokinin, secretin, glucagon-like peptide 1 and 2, peptide YY, vasoactive intestinal peptide; 3) Stimulation of pancreatic and biliary secretions (Fedorak, 2009).

\section{CLINICAL MANIFESTATION AND COMPLICATIONS}

Clinical features of SBS patients result from the intestinal adaptation process through three stages. The first stage (acute stage), lasts 1-2 weeks, characterized by excessive diarrhea. During this stage, water, electrolytes, and nutrients are provided via the parenteral route. The second stage (the period of intestinal adaptation), lasts 2-24 months, when the oral intake begins and is increased gradually. Enteral/parenteral, full or partial supplementation, usually necessary to maintain optimal nutrition. At the third stage (long-term management stage), maximal intestinal adaptation is reached, and normal oral intake may occur. Some patients who cannot reach the full oral nutrition stage, can continue with a combination of enteral or parenteral nutrition at home (Fedorak, 2009).

The following are the clinical manifestations and complications of SBS patients:

1. Malabsorption of macronutrients, liquids, and electrolytes

After intestinal resection, the carbohydrates from the small intestine go to the colon, where they are metabolized by bacteria to SCFA (short-chain fatty acids). SCFA causes diarrhea through two mechanisms that cause osmotic diarrhea, and directly stimulate the colon to secrete fluid and electrolytes. Liquids and electrolytes can disappear a lot and often occur during the first few weeks after bowel resection.

2. Deficiency of vitamins and minerals (micronutrients)

Vitamin B12 deficiency often occurs after ileal resection because the intrinsic receptor of vitamin B12 is limited to the ileum, but bacteria in the small intestine and colon can metabolize vitamin B12, thus increasing deficiency. Water-soluble vitamins are absorbed both through the entire small intestine and are generally available sufficiently. Steatorrhea is related to the decrease of fat-soluble vitamins, particularly vitamin D, A, K and (rarely) E. Most human vitamin $\mathrm{K}$ is obtained from synthesis by colonic bacteria $(60 \%)$, so patients with colon have a low risk of deficiency (Buchman, 2010). Mineral deficiency includes calcium and magnesium commonly occurring, secondary to malabsorption of fatty acids, thus forming a complex with this divalent cation. Calcium deficiency can also be triggered by vitamin D malabsorption.

\section{Diarrhea}

Several factors make diarrhea inevitable from patients with large bowel resection due to reduction of absorption surface area; decreased intestinal transit time; gastric hypersecretion, small intestine, and colon; increased osmolality of the contents of the colon with osmotic diarrhea, secondary to carbohydrate and fat malabsorption.

4. Gastric Hypersecretion

Gastric hypersecretion occurs during 6-12 months after resection, secondary to hypergastrinemia, which occurs due to loss of hormone inhibitors produced in the proximal intestine. Gastric hypersecretion causes loss of fluid and excessive electrolytes, and decreases intestinal absorption, and peptic esophagitis/ulcers arise.

5. Calcium oxalate kidney stones

Fat malabsorption, secondary to bile acid deficiency in patients with extensive ileal resection and the presence of intact colon, is associated with an increased risk of oxalate kidney stones. Oxalates in food usually settle as calcium oxalate in the intestinal lumen, and exit through the stools. Malabsorption of fat in SBS patients causes unabsorbed LCFA to compete between oxalate towards calcium present in the intestinal lumen. As a result, large amounts of free oxalate are present in the colon, and are absorbed and then excreted through the kidneys, manifesting as hyperoxaluria or form calcium oxalate stones, as shown in Figure 3. Management of hyperoxaluria is limiting foods intake containing oxalate. Oral calcium citrate may be administered because extra calcium precipitate the oxalate and citrate diet to prevent the formation of stones in the urine.

6. Gallstones

The incidence of gallstones increases three-fold after ileal resection. Disorders of bile enterohepatic circulation and bile salts malabsorption result due to ileal resection, disrupting the composition of the bile organic component of hepatic bile acids, cholesterol, and phospholipids, leading to an increase in 
cholesterol synthesis so bile becomes supersaturated with cholesterol, and gallstones form. Most patients with ileostomy have biliary stones containing calcium compared to gallstones of radiolucent cholesterol.

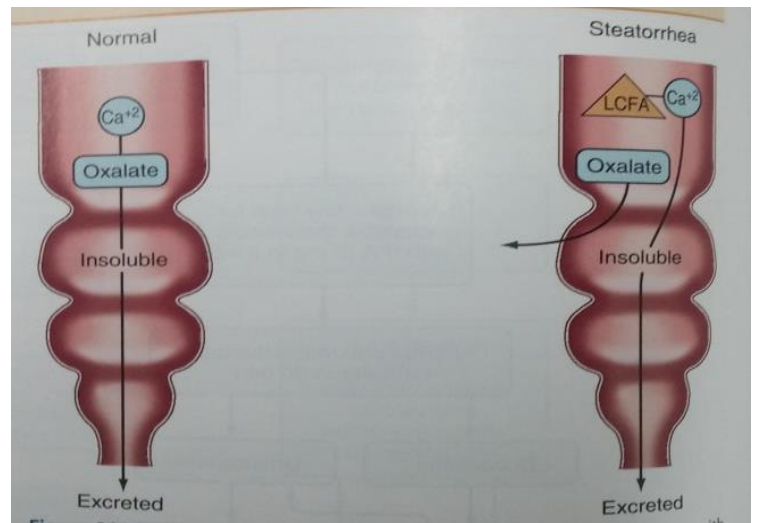

Figure 3: The mechanism of oxalate hyper absorption in SBS patients with steatorrhea (Buchman, 2010)

\section{Liver disease}

Incidence of liver disease increases up to $65 \%$ in SBS patients requiring long-term TPN, manifesting as cholestasis, steatosis or steatohepatitis, and hepatic dysfunction. After 5 years of TPN use, more than $50 \%$ of SBS patients have severe liver disease. Liver failure occurs in $15 \%$ of SBS patients who depend on TPN. This may be due to a lack of enteral intake and decreased gastrointestinal or gastrointestinal secretion due to episodes of sepsis, including bacterial translocation through the permeable bowel epithelium. Vascular factors may also play a role in hepatic dysfunction, where portal blood flow disruption is a factor. Hepatic steatosis is associated with excess lipid content in TPN and deficiency of essential fatty acids. Cholestasis correlates with the extent of gut that is resected in adulthood, prematurity and low birth weight in infants. Liver disease may be an indication for bowel transplantation, with or without a liver transplant.

\section{D-Lactic Acidosis}

This is a rare complication of SBS and is only observed in patients with intact colon. The incidence of acidosis is usually triggered by increased oral intake of excess carbohydrates. Unabsorbable carbohydrates are metabolized by colonic bacteria to SCFA and lactate, which decreases intracolonic PH. The low $\mathrm{pH}$ inhibits especially the growth of Bacteroides species and promotes the growth of acid-resistant bacteria, anaerobic gram-positive (Bifidobacterium, Lactobacillus, and Eubacterium), which have the ability to produce D-lactate (in contrast to L-lactate produced in normal metabolic processes). D-lactate is absorbed from the colon and is metabolized by humans due to lack of D-lactate dehydrogenase enzyme. The main excretion of Dlactate is by the kidneys. D-lactate absorption leads to an increase in metabolic acidosis. The management consists of correcting acidosis with sodium bicarbonate and reducing oral intake of carbohydrates.

9. Wound and infection healing

As a result of macro and micronutrient malabsorption, wound healing becomes impaired in SBS. In experimental animals, mice with extensive resection of the intestine exhibited poor collagen synthesis and a decrease in the strength of anastomosis resulting in dehiscence or stenosis. The loss of integrity of the epithelial barrier and bacterial translocation is positively correlated with the loss of the ileocecal valve. In animal experiments with SBS, the bacterial translocation rate increased with an $87 \%$ incidence as a result of excess bacterial growth in the rest of the intestine (Fedorak, 2009).

10. Metabolic bone disease

Patients with SBS have an increased risk of osteomalacia, osteoporosis, and secondary hyperparathyroidism. Specific risk factors are the effects of parenteral nutrition, macro malabsorption and micronutrients (e.g. vitamin D, hypocalcemia, hypomagnesemia), and chronic metabolic acidosis. Management includes correction of calcium, magnesium and vitamin D deficiency, and correction of metabolic acidosis (Buchman, 2010).

11. Complications related to catheters

The majority of patients receiving long-term TPN face complications related to central venous catheters, i.e. infections, and mechanical problems such as occlusion and catheter damage (Buchman, 2010).

\section{MANAGEMENT}

\subsection{Management of nutrients, fluids, and electrolytes}

Nutritional management for SBS patients is a dynamic process that follows the evolution of the clinical stage of bowel adaptation. In the immediate postoperative period, all patients undergoing temporary fasting bowel resection require TPN support. If the intestinal residual is more than $25 \%$, parenteral nutrition may be subsequently discontinued (Fedorak, 2009). The patient remains fasting for 5-10 days, for healing of enteric anastomosis, and for assessing basal loss of fluids 
and electrolytes. Enteral feeding, followed by oral feeding, begins in the later postoperative phase when the hemodynamic patient is stable, the return of intestinal blood flow is adequate, and the postoperative ileus is reduced. Early oral feeding is important for intestinal adaptation. The calorie intake is improved slowly until the target is reached (Fedorak, 2009). The clinical assessment of SBS patients includes measurement of fluid adequacy, electrolytes, and nutritional status. Macronutrient needs can be seen Table 2 .

Table 2: Macronutrient recommendations in short bowel syndrome (Buchman, 2010)

\begin{tabular}{|c|c|c|}
\hline & With colon & Without colon \\
\hline \multirow[t]{2}{*}{$\begin{array}{l}\text { Carbohy } \\
\text { drate }\end{array}$} & $\begin{array}{l}\text { Complex } \\
\text { carbohydrate }\end{array}$ & Varied \\
\hline & $\begin{array}{l}30-35 \mathrm{kcal} / \mathrm{kg} / \mathrm{day} \\
\text { Soluble fiber }\end{array}$ & 30-35 kcal/kg/day \\
\hline \multirow[t]{2}{*}{ Fat } & $\mathrm{MCT} / \mathrm{LCT}$ & LCT \\
\hline & $\begin{array}{l}20 \%-30 \% \text { of } \\
\text { calorie intake } \\
\pm \text { low fat/high fat }\end{array}$ & $\begin{array}{l}20 \%-30 \% \text { of calorie } \\
\text { intake } \\
\pm \text { low fat } / \text { high fat }\end{array}$ \\
\hline \multirow[t]{2}{*}{ Protein } & Protein intact & $\begin{array}{l}\text { Protein intact } \\
10-15 \sigma / k \sigma / d a y\end{array}$ \\
\hline & $\begin{array}{l}1.0-1.5 \mathrm{~g} / \mathrm{kg} / \mathrm{day} \\
\pm \quad \text { formula } \\
\text { peptide-based }\end{array}$ & $\begin{array}{l}1.0-1.5 \mathrm{~g} / \mathrm{kg} / \mathrm{day} \\
\pm \text { formula peptide- } \\
\text { based }\end{array}$ \\
\hline
\end{tabular}

SBS patients with the availability of colon, should be given a diet high in complex carbohydrates, such as starch, nonstarch polysaccharides, and soluble fiber. The material is usually not absorbed in the small intestine, but when in the colon, colon bacteria ferment it into SCFA such as butyrate, acetate, and propionate. About 75 mmol SCFA is produced from $10 \mathrm{~g}$ of unabsorbed carbohydrate. Patients with intact colon can absorb up to $310-740 \mathrm{kcal}(1.3-31 \mathrm{MJ})$ daily when fed a diet of $60 \%$ carbohydrates.

Home TPN is used by patients requiring longterm TPN after hospitalization. TPN fluid is usually hypertonic, so it should be administered through a central vein, to reduce the risk of infection and thrombosis. Patients need to be informed of TPN indications, proper catheter care, dressing mode, pump use, TPN solution preparation, as well as acute TPN complications including air embolism, hypoglycemia, and catheter-related infections (Buchman, 2010).

\subsection{Pharmacological Management}

Drug absorption is usually impaired in SBS. Most drugs are absorbed in the proximal jejunum. Oral and enteral delivery routes should be used as much as possible to avoid additional manipulation of central venous catheters. A liquid or sublingual drug formula will give the best results of pharmacokinetic absorption compared to pills (Fedorak, 2009).

a. Biliary supplementation

When more than $100 \mathrm{~cm}$ of ileum is resected, fat malabsorption may occur (fat-soluble vitamin deficiency also occurs), because bile salt malabsorption decreases micelle formation, leading to poor lipid solubilization. Bile salt replacement therapy is performed with ox bile or synthetic conjugated bile acid (cholylsarcosine), dose of 2 $\mathrm{g} /$ meals, increased fat absorption in the small intestine proximal, decreased urinary oxalate excretion, and decreased oxalate nephrolithiasis in intestinal resection patients with intravenous colon. Thus, it can be a therapy option for patients with an oxalate stone formation history. The bile acidsequestering agent, cholestyramine, is useful for reducing bile salt-related diarrhea in patients with ileal terminal resection of less than $100 \mathrm{~cm}$ (Buchman, 2010).

Table 3: Recommendation regarding vitamin and minerals in short bowel syndrome.

\begin{tabular}{|c|c|}
\hline Micronutrient & Requirements \\
\hline Vitamin A & $10,000-50,000$ units/day \\
\hline Vitamin B12 & $\begin{array}{l}1,000 \mu \mathrm{g} \text { subcutaneous/month (for } \\
\text { patients with ileal terminal } \\
\text { resection/disease) }\end{array}$ \\
\hline Vitamin $\mathrm{C}$ & $200 \mathrm{mg} /$ day \\
\hline Vitamin D & $\begin{array}{l}50,000 \text { unit of } 1.25(\mathrm{OH} 2)-\mathrm{D} 3 \text { twice } \\
\text { a week to twice a day }\end{array}$ \\
\hline Vitamin E & $30 \mathrm{IU} /$ day \\
\hline Vitamin $\mathrm{K}$ & $10 \mathrm{mg} /$ week \\
\hline Calcium & $1,000-1,500 \mathrm{mg} /$ day \\
\hline Magnesium & $\begin{array}{l}30 \mathrm{ml} \text { twice a day (magnesium } \\
\text { glucoheptonate liquid) }\end{array}$ \\
\hline Ferum $(\mathrm{Fe})$ & $\begin{array}{l}300 \mathrm{mg} \text { twice a day (ferrous sulfate } \\
\text { liquid) }\end{array}$ \\
\hline Selenium & $60-150 \mu \mathrm{g} /$ day \\
\hline Zinc & $\begin{array}{l}220-440 \mathrm{mg} / \text { day (in sulfate or } \\
\text { gluconate form) } \\
\text { If needed }\end{array}$ \\
\hline Bicarbonate & \\
\hline
\end{tabular}

b. Management of gastric hypersecretion

The use of a proton pump inhibitor or histamine $\mathrm{H} 2$ receptor blocker is needed to suppress hypersensitivity of gastric acid induced by hypergastrinemia (Buchman, 2010; Lamprecht, 2015).

c. Diarrhea management

Opiates are an antimotility drug used for SBSrelated diarrheal therapy. Opiate preparations include natural preparations (e.g. paregoric and 
opium alkaloids), and synthetic preparations (including codeine, diphenoxylate, and loperamide). Antidiarrheal drugs should be taken 1 hour before meals. Octreotide, a long-acting somatostatin analog, may slow the intestinal transit and increase absorption, but it can also decrease splanchnic protein synthesis inhibiting post resection gastric adaptation, and also increase the risk of gallstones by the inhibitory effect on gallbladder contractions (Fedorak, 2009; Buchman, 2010; Seetharam and Rodrigues, 2011). The $\alpha$ 2-adrenergic agonist (Clonidine) is a potent intestinal absorption stimulator, and decreases intestinal motility, but due to the effects of central and sedative hypotension, its use is limited as an antidiarrheal drug. If diarrhea is caused by bile acid malabsorption, treatment with bile acid-binding resins, such as cholestyramine (2-4 $\mathrm{g}$ at mealtime) or colestipol (1-2 $\mathrm{g}$ at mealtime) will reduce diarrhea (Buchman, 2010). Some medications to reduce diarrhea can be seen in Table 4.

Table 4: Treatment used to reduce diarrhea (Fedorak, 2009)

\begin{tabular}{ll}
\hline \multicolumn{1}{c}{ Drug } & \multicolumn{1}{c}{ Dose } \\
\hline $\begin{array}{l}\text { Loperamide } \\
\text { Diphenoxylate- } \\
\text { atropine }\end{array}$ & $4-6 \mathrm{mg}, 4 \mathrm{x} /$ day \\
Codeine & $2.5-5 \mathrm{mg}, 4 \mathrm{x} /$ day \\
phosphate & $15-30 \mathrm{mg}, 2-4 \mathrm{x} /$ day \\
Tincture opium & $0.6 \mathrm{ml}(2.5 \mathrm{mg}), 2-4 \mathrm{x} /$ day \\
Ranitidine & $300 \mathrm{mg}, 2 \mathrm{x} /$ day \\
Omeprazole & $40 \mathrm{mg}, 2 \mathrm{x} /$ day \\
Octreotide & $50-100 \mu \mathrm{g}$ subcutaneous, \\
& $2 \mathrm{x} / \mathrm{day}$ \\
Clonidine & $0.3 \mathrm{mg}$ transcutaneous patch, \\
& $1 \mathrm{x} / \mathrm{week}$ \\
\hline
\end{tabular}

d. Trophic therapy to improve bowel adaptation

This is the latest trophic therapy to strengthen the endogenous process of intestinal adaptation. A study was conducted on phase III of two available pharmacologic therapies for PN-dependent SBS patients, Teduglutide (glucagon-like peptide 2 analog/GLP-2) and Somatropin (recombinant human growth hormone). In these studies, both therapies were reported to increase the capacity of intestinal absorption and to decrease PN volume requirements (Storch, 2014). Data on the effects of both drugs are limited, so their use is not recommended for routine use (Van Gossum et al., 2009; Seetharam and Rodrigues, 2011; Jeppesen, 2014; Storch, 2014). The SBS management algorithm can be seen in Figure 4.

\subsection{Surgical Management}

\subsubsection{Procedure to extend the gut}

The most important surgical procedure is the residual colon reanastomosis of residual colon because it has a low rate of mortality and morbidity. Other procedures, such as tapering enteroplasty, intestinal valve manufacture, recirculating loops, reversal of intestinal segment or colonic interposition, are intended to prolong transit time but the procedure is still experimental and its use is limited, and outcomes are usually not optimal. Bianchi procedure (longitudinal intestinal lengthening and tailoring), may be useful for patients with segmental dilatation and nonfunctional bowel due to dysmotility and bacterial overgrowth. Another procedure that is serial transverse enteroplasty is more useful than Bianchi because the technique is simpler, and there is no transection of the intestine, making it easier to supply blood supply to the intestine (Buchman, 2010; Seetharam and Rodrigues, 2011).

\subsubsection{Bowel transplantation}

Intestinal transplantation is a life-saving procedure that needs to be considered in patients with irreversible intestinal failure with parenteral nutrition. In adult recipients, $21 \%$ need a combination of intestinal and liver transplants, 55\% intestine, and $24 \%$ multivisceral transplantation. In 2003 from the international small intestinal transplant registry, the 1-year graft/patient survival rate was $67 \% / 77 \%$ for small bowel transplants, $59 \% / 60 \%$ for intestinal and liver combinations, and $61 \% / 66 \%$ for multivisceral transplants. The results are the same for child and adult transplants. About $80 \%$ of transplant survivors may quit parenteral nutrition and use oral nutrition, $10 \%$ have partial or non-functional transplant function, and $10 \%$ of transplants are stabilized (Fedorak, 2009).

\section{PROGNOSIS}

Prognostic factors in SBS include residual intestinal length, presence of residual underlying disease, presence or absence of colon and an ileocecal valve, patient age, dependency on an enteral diet, and nature of the underlying disease (Lamprecht, 2015). In children, survival without enteral or TPN 
supplements can usually occur when the length of the small intestine is more than $40 \mathrm{~cm}$ (at least $20 \%$ of normal length), while in adults survival is possible if the length of the remaining small intestine is more than $150 \mathrm{~cm}$ (at least $25 \%$ of normal length), measured from the Treitz ligament. In adults, the 5-year survival rate is $55 \%$ and dependence on parenteral nutrition is about $45 \%$, while in children the 5 -year survival rate is $73 \%$ and
$75 \%$. Survival is negatively correlated with endenterostomy, ileocecal valve retrieval, colon resection, small bowel length less than $50 \mathrm{~cm}$ (adult) and $15 \mathrm{~cm}$ (child), advanced persistent cholestatic jaundice, and arterial infarction that causes SBS. Dependence on parenteral nutrition is positively correlated with a small bowel length of less than 100 $\mathrm{cm}$, absence of ileum, ileocecal valve, or colon (Fedorak,

2009).

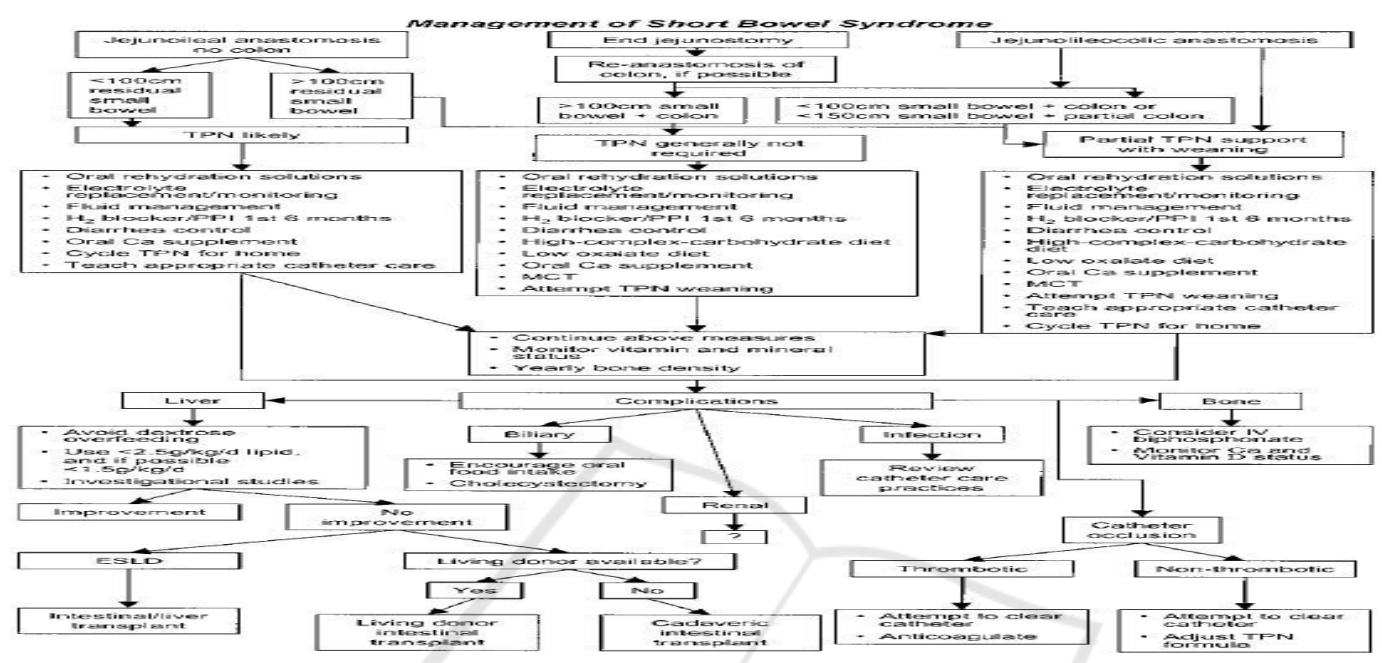

Figure 4: Pump management algorithm of short bowel syndrome.

\section{CONCLUSION}

Short bowel syndrome is malabsorption due to intestinal surface area insufficiency, occurring when the remaining small intestine is less than 200 $\mathrm{cm}$. There are three types of SBS bowel resection types, namely ileocolonic, jejunocolonic, and jejunostomy. The main causes of SBS in adults are intestinal resection associated with vascular disorders and Crohn's disease. SBS management includes nutrition management, pharmacological management and surgical management.

\section{REFERENCES}

BUCHMAN, A. L. 2010. Short Bowel Syndrome, USA, Elsevier.

FEDORAK, R. N. A. B., L. 2009. Short Bowel Syndrome, USA, Wiley-Blackwell Publishing.

JEEJEEBHOY, K. N. 2002. Short bowel syndrome: a nutritional and medical approach. CMAJ, 166, $1297-$ 302.

JEPPESEN, P. B. 2014. Pharmacologic options for intestinal rehabilitation in patients with short bowel syndrome. JPEN J Parenter Enteral Nutr, 38, 45S$52 \mathrm{~S}$.

LAMPRECHT, G. 2015. [Short bowel syndrome and intestinal failure - new developments]. Dtsch Med Wochenschr, 140, 1842-4.
SEETHARAM, P. \& RODRIGUES, G. 2011. Short bowel syndrome: a review of management options. Saudi J Gastroenterol, 17, 229-35.

STORCH, K. J. 2014. Overview of short bowel syndrome: clinical features, pathophysiology, impact, and management. JPEN J Parenter Enteral Nutr, 38, 345-356.

TAPPENDEN, K. A. 2014. Pathophysiology of short bowel syndrome: considerations of resected and residual anatomy. JPEN J Parenter Enteral Nutr, 20, $1-9$.

VAN GOSSUM, A., CABRE, E., HEBUTERNE, X., JEPPESEN, P., KRZNARIC, Z., MESSING, B., POWELL-TUCK, J., STAUN, M., NIGHTINGALE, J. \& ESPEN 2009. ESPEN Guidelines on Parenteral 
Nutrition: gastroenterology. European Society for Clinical Nutrition and Metabolism, 28, 745-780.

WALL, E. A. 2013. An overview of short bowel syndrome management: adherence, adaptation, and practical recommendations. J Acad Nutr Diet, 113, $1200-8$. 